\title{
Fruit Production, Migrant Bird Visitation, and Seed Dispersal of Guarea glabra in Panama
}

\author{
${ }^{1}$ Henry F. Howe and ${ }^{2}$ Diane De Steven \\ ${ }^{1}$ Program in Evolutionary Ecology and Behavior, Department of Zoology, University of Iowa, \\ Iowa City, Iowa 52242 and \\ ${ }^{2}$ Museum of Zoology and Department of Ecology and Evolutionary Biology, University of Michigan, \\ Ann Arbor, Michigan 48109 USA
}

\begin{abstract}
Summary. The relationship between bird visitation and the size of the available fruit crop was studied at an understory tree (Guarea glabra Vahl, Meliaceae) in the tropical wet forest of Barro Colorado Island, Panama Canal Zone. Twelve resident species and seven North American migrant species fed on the bright orange arilloids (seeds with arils), which were not depleted during the normal fruiting period. The number of individual visitors, the number of visiting species, and the number of seeds removed increased linearly with the size of the available fruit crop. The proportion of seeds removed did not increase with the size of the available fruit crop, indicating that dispersal is a function of the number of fruit available and not a disproportionate function of large fruit displays. Four species of North American migrants (Myiarchus crinitus, Catharus ustulatus, Vireo olivaceus, and Vermivora peregrina) accounted for $70 \%$ of the visits and $60 \%$ of the seeds removed from the trees. No resident species visited Guarea as frequently as any one of these migrants. There was no indication that any single visitor was dependent on this tree for nutrition, nor that the tree was dependent upon any single species for dispersal. We hypothesize that the fruiting season of G. glabra is adaptively synchronized with northward migration of opportunistically frugivorous North American birds.
\end{abstract}

\section{Introduction}

In Central American forests, most trees are pollinated by animals and bear fruit adapted for the attraction of vertebrate seed dispersers (Bawa, 1974; Frankie et al., 1974). Both sets of interactions have probably played a crucial role in the evolution of communities dominated by angiosperms (Regal, 1977), and both are important to the understanding of contemporary tropical communities (cf. Howe, 1977). The implications of pollinator constancy have received critical attention (e.g. Baker and Hurd, 1968), but the coevolutionary and ecological implications of differences in disperser constancy have remained nebulous 
for lack of appropriate information. Snow (1971) speculated that plants benefit from a high diversity of seed vectors, implying that adaptive strategies of fruit production, presentation, and reward should be "designed" to attract the greatest variety of dispersers possible. McKey (1975) suggested that such a tactic might be associated with high fecundity plants that produce a large number of fruit of low nutritional quality; other species with "energetically expensive" large seeds should offer rewards that attract a restricted but reliable set of dispersers.

The general perspective offered by McKey has been elaborated for both intra- and interspecific comparisons (Howe and Estabrook, 1977). In species with large seeds and nutritious rewards, plants that limit the number of fruit available per day should promote competition and specialization among potential dispersers. This should result in effective dissemination of the entire fruit crop. Ineffective dispersal may occur for individuals producing unusually low or high daily crops (cf. Howe and Vande Kerckhove, 1978). For species with small seeds and rewards of low nutritional quality, competition among birds should be negligible, and the effectiveness of dispersal should increase with crop size through attraction of a large number and variety of opportunistic frugivores. If Snow (1971) is correct, this should ensure dissemination to a wide variety of sites. Increasing fruit displays might also enhance the proportion of seeds removed by drawing disproportionate numbers of frugivores (Howe and Estabrook, 1977; cf. Janzen, 1967).

We tested predictions relating bird visitation and seed dispersal for an understory tree bearing superabundant fruit, Guarea glabra Vahl (Meliaceae), in the tropical wet forest of Barro Colorado Island, Panama Canal Zone. Conspicuous displays of ripening and open fruit capsules, bright orange arils separable from the seeds, and seed presentation during daylight hours clearly place G. glabra within the syndrome of bird-dispersed plants described by van der Pijl (1972). Seeds are small, the aril offers little gross nutrition $(<0.1 \mathrm{~g})$, and arilloids are virtually always visible on or under trees during the fruiting season, suggesting that depletion is rare. These features correspond to the ecological syndrome of fruit superabundance discussed by McKey (1975) and by Howe and Estabrook (1977). We expected a heterogeneous assemblage of frugivores with the following characteristics and effects upon the plant: (1) an increase in visitation with daily crop size, (2) an increase in assemblage richness with daily crop size, (3) sporadic visitation by members of any given species, (4) low or negligible aggressive interactions among visitors, (5) an increase in the number of seeds removed with daily crop size, and (6) an increase in dispersal success (percent of available seeds taken) with daily crop size. As seeds were available when North American migrants were present, such opportunists were expected to be important components of the assemblage (McKey, 1975; Howe and Estabrook, 1977). Predictions (5) and (6) are not independent of previous ones, but carry different implications. Large plants are always likely to disperse more seeds than small ones by virtue of differences in total crop size of one to ten orders of magnitude and by the tendency of foraging animals to find and utilize abundant food sources. But an increase in the number of seeds dispersed with crop size need not imply special adaptations for attracting dispersers though supernormal displays. The enhanced dispersal may be an effect of fecundity. On the other 
hand, a disproportionately large number and variety of animals might be attracted to supernormal displays (cf. Janzen, 1967; Howe and Estabrook, 1977). This could suggest a strong advantage of display that is in some sense independent of fecundity itself.

\section{Materials and Methods}

Fruiting Guarea glabra trees were located and observed in the tropical wet forest of Barro Colorado Island, Panama Canal Zone, from 20 March through 11 May 1978. This period spanned the fruiting season of this species at the site, as very few fruit were available two weeks before and after these dates. Leigh and Smythe (1978) give a detailed description of the site. Eleven trees were selected for which crowns were visible from the ground, thereby permitting observation of animal activity and counts of fruiting capsules. All were in shaded understory situations characteristic of the population.

Animal observations were made during 12 periods of $5 \mathrm{~h}$ duration (ca. 0630-1130 h). During each continuous watch, one observer noted (1) the species, time of arrival, and time of departure of each visitor that attempted to eat fruit, and (2) the number of arilloids ingested per visit by each visitor. As foliage obscured much of the feeding activity, reliable counts of the number of seeds eaten per visit were far less numerous than recorded visits. Consequently, the number of arilloids eaten for each $5 \mathrm{~h}$ watch was estimated by multiplying the number of visits recorded for each species by the mean number of seeds eaten per visit by that species for complete observations. This method clearly invalidates species-specific comparisons of feeding rates between individual plants, but gives a rough estimate of disperser activity. Six visiting species were known to eat the arilloids, but complete observations were not obtained. The number of seeds eaten per visit by these birds was estimated from regression of known mean feeding rates on weight of species for which complete observations were obtained. This method is adequate for a general description of the dispersal system, as the species with incomplete data were infrequent visitors. Weights of birds observed eating Guarea fruits were obtained from specimen labels in the Museum of Zoology, University of Michigan. For tropical species, specimens collected in Central America were used. For North American migrants, such data were unavailable and weights of birds collected in the United States were used instead. As the weights of different species varied by an order of magnitude (11 to $399 \mathrm{gm}$ ), error introduced by use of North American birds is negligible.

During each continuous watch in the field, the observer counted (1) the number of capsules on the tree, (2) the number of open capsules with arilloids visible on the tree, and (3) the number of capsules on the ground under the crown. These provide estimates of total crop size and daily availability, as each capsule contained 4 seeds. These $60 \mathrm{~h}$ of observation included 55 for which all of the above data were collected at 11 trees. An additional period of observation was added when an observer failed to count available arilloids on the first day of observation. In late April, the trees were revisited for estimation of height (to $1 \mathrm{~m}$ ), crown radius (to $0.5 \mathrm{~m}$; estimated as the mean of 4 radii measured at 4 points of the compass), and measurement of diameter at breast height (to $1 \mathrm{~cm}$ ). Standard deviations accompany means.

\section{Results}

Description of the Tree

Guarea glabra Vahl is a forest understory tree of moderate size with a wide mainland distribution from Mexico to Columbia, Ecuador, and Venezuela (Smith, 1965). Populations also occur in the West Indies. On Barro Colorado Island, the species is a moderately common tree in shaded situations in both second growth (60 years old) and older forest ( $120+$ years). The eleven individ- 


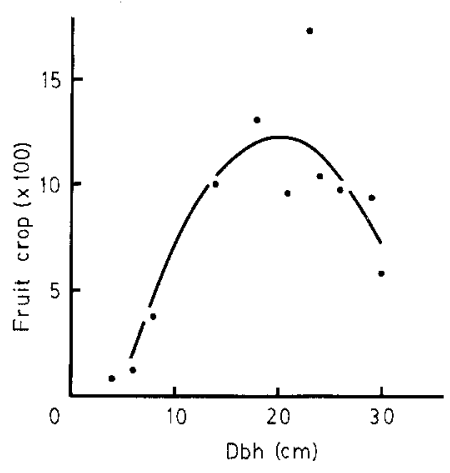

Fig. 1. Fruit production as a function of tree size, as estimated by diameter at breast height $(d b h)$. The best fit is curvilinear: no. of fruit $=-866.7+206.8 \mathrm{dbh}-5.1 \mathrm{dbh}^{2}\left(r^{2}=0.82\right.$, $P=0.001)$

uals used in this study varied from 6 to $30 \mathrm{~cm}$ in diameter at breast height (dbh) $(\bar{x}=18 \pm 9)$ and from 3 to $12 \mathrm{~m}$ in height $(\bar{x}=8 \pm 4)$. Mean crown radii for the trees varied from 1 to $5 \mathrm{~m}(\bar{x}=3 \pm 1)$. Four arilloids are borne in capsules from 13.9 to $91.2 \mathrm{~mm}$ long $(\bar{x}=16.6 \pm 1.4)$ and from 12.9 to $17.6 \mathrm{~mm}$ wide $(\bar{x}=14.8 \pm 1.3)$. Arilloids consist of a thick-walled seed surrounded by a bright orange aril approximately 0.1 to $0.5 \mathrm{~mm}$ thick. The entire unit varies from 7.5 to $11.6 \mathrm{~mm}$ long $(\bar{x}=10.0 \pm 0.9)$ and 5.0 to $7.4 \mathrm{~mm}$ wide $(\bar{x}=6.3 \pm 0.5)$. The sample size for these measures is 20 . The total fruit crop in the study trees ranged from 8 to $1735(\bar{x}=813 \pm 502)$, with a corresponding seed crop size of 32 to $6940(\bar{x}=3254 \pm 2010)$. The number of fruit borne by a tree is correlated with size, as measured by dbh (Fig. 1). A linear fit is significant but weak $\left(r^{2}=0.41, P<0.05\right)$, while a curvilinear fit is much stronger $\left(r^{2}=0.82\right.$, $P=0.001$ ). Even with a small sample, this suggests senescence among larger trees (cf. Melampy and Howe, 1977). Fruiting capsules appeared to open throughout the day, with 1 to $132(\bar{x}=46 \pm 46)$ visible during watches at particular trees. These represented 1.2 to $12.5 \%(\bar{x}=6.2 \pm 3.7)$ of the total seasonal fruit crop of a tree available at any one time. In one instance, a small group of vireos appeared to deplete seeds in the four capsules open on a tree; otherwise depletion was not obvious at the end of five-hour watches. Many arilloids on the trees or ground appeared discolored from exposure to air; these were probably exposed for more than one day without being eaten.

\section{Visitor Constancy}

Nineteen species of birds attempted or succeeded in eating the arilloids. This was a taxonomically and biologically diverse assemblage, representing 16 genera and 10 families and a size range from 11 to $399 \mathrm{~g}$. Twelve were residents of Panama and seven were migrants that winter in Central or South America, but breed in North America (Table 1). Striking differences occurred in measured or estimated rates of seed removal (seeds eaten per visit), total visitation, and, consequently, total contribution to seed removal (Table 2). The maximum number of seeds eaten per species, representing an hypothetical "optimum" for the plant, ranged from 1 to 22 seeds per visit. But the realized means 
Table 1. Taxa, migratory status, and weights of 19 species of birds observed eating seeds of Guarea glabra in Panama. Weights are from museum labels

\begin{tabular}{|c|c|c|c|}
\hline $\begin{array}{l}\text { Family } \\
\text { Binomial (common name) }\end{array}$ & Status $^{a}$ & $N$ & $\mathrm{~g}(\bar{x} \pm \mathrm{SD})$ \\
\hline \multicolumn{4}{|l|}{ Trogonidae } \\
\hline Trogon massena (Slaty-tailed Trogon) & resident & 10 & $145 \pm 12$ \\
\hline T. rufus (Black-throated Trogon) & resident & 6 & $55 \pm 3$ \\
\hline T. violaceus (Violaceous Trogon) & resident & 15 & $59 \pm 4$ \\
\hline \multicolumn{4}{|l|}{ Ramphastidae } \\
\hline Pteroglossus torquatus (Collared Aracari) & resident & 10 & $229 \pm 11$ \\
\hline Ramphastos sulfuratus (Keel-billed Toucan) & resident & 15 & $399 \pm 35$ \\
\hline \multicolumn{4}{|l|}{ Picidae } \\
\hline Melanerpes pucherani (Black-cheeked Woodpecker) & resident & 6 & $66 \pm 7$ \\
\hline \multicolumn{4}{|l|}{ Pipridae } \\
\hline Pipra mentalis (Red-capped Manakin) & resident & 15 & $16 \pm 2$ \\
\hline \multicolumn{4}{|l|}{ Cotingidae } \\
\hline Rhytipterna holerythra (Rufous Mourner) & resident & 7 & $41 \pm 2$ \\
\hline Tityra semifasciata (Masked Tityra) & resident & 15 & $84 \pm 7$ \\
\hline Querula purpurata (Purple-throated Fruitcrow) & resident & 6 & $110 \pm 12$ \\
\hline \multicolumn{4}{|l|}{ Tyrannidae } \\
\hline Myiodynastes maculatus (Streaked Flycatcher) & resident & 6 & $46 \pm 1$ \\
\hline Myiarchus crinitus (Crested Flycatcher) & migrant & 15 & $35 \pm 3$ \\
\hline M. tuberculifer (Dusky-capped Flycatcher) & resident & 15 & $17 \pm 2$ \\
\hline Contopus spp. (Pewee) & migrant & 10 & $13 \pm 1$ \\
\hline \multicolumn{4}{|l|}{ Turdidae } \\
\hline Catharus ustulatus (Swainson's Thrush) & migrant & 15 & $32 \pm 2$ \\
\hline \multicolumn{4}{|l|}{ Vireonidae } \\
\hline Vireo olivaceus (Red-eyed Vireo) & migrant & 15 & $17 \pm 1$ \\
\hline \multicolumn{4}{|l|}{ Parulidae } \\
\hline Vermivora peregrina (Tennessee Warbler) & migrant & 15 & $11 \pm 2$ \\
\hline Dendroica pensylvanica (Chestnut-sided Warbler) & migrant & 15 & $11 \pm 1$ \\
\hline \multicolumn{4}{|l|}{ Thraupidae } \\
\hline Piranga rubra (Summer Tanager) & migrant & 15 & $30 \pm 3$ \\
\hline
\end{tabular}

a "Migrant" status indicates a species that breeds in North America and normally winters in Central or South America

were much lower, ranging from 1 to 11 and averaging $2.3 \pm 2.2$. The reason may have been that visitors had sufficient nutrition from other foods ingested before they arrived at the tree, but it may also reflect avoidance of predation (cf. Howe, 1977; Howe and Vande Kerckhove, 1978). Small and very common visitors in particular (e.g. Catharus, Vireo and Vermivora) characteristically made repeated visits to the trees from neighboring vegetation 10 to $20 \mathrm{~m}$ away. Both the maximum number of seeds eaten per visit and the mean number increased with the weight of the visitor. These relationships are:

Max. seeds/visit $=0.04 \mathrm{~g}+1.78\left(r^{2}=0.88, n=14, P<0.01\right)$

Mean seeds/visit $=0.02 \mathrm{~g}+0.86\left(r^{2}=0.57, n=14, P<0.05\right)$ 
Table 2. Visitation and seed removal by 19 avian frugivores at Guarea glabra in Panama

\begin{tabular}{|c|c|c|c|c|c|c|}
\hline \multirow[t]{2}{*}{ Species } & \multirow{2}{*}{$\begin{array}{l}\text { Days } \\
\text { seen } \\
(N)\end{array}$} & \multirow{2}{*}{$\begin{array}{l}\text { Visits } \\
(N)\end{array}$} & \multicolumn{4}{|c|}{ Seeds/visit } \\
\hline & & & Range & $\bar{x}$ & $\mathrm{~N}^{\mathrm{a}}$ & $\%$ taken $^{b}$ \\
\hline Trogon massena & 1 & 3 & 34 & 3.7 & 3 & 2 \\
\hline T. rufus & 3 & 10 & $1-2$ & 1.7 & 6 & 3 \\
\hline T. violaceus ${ }^{\mathrm{c}}$ & 1 & 2 & $0-4$ & 2.1 & - & 1 \\
\hline Pteroglossus torquatus & 3 & 11 & $0-8$ & 3.2 & 6 & 7 \\
\hline Ramphastos sulfuratus & 3 & 4 & 0.22 & 11.0 & 2 & 8 \\
\hline Melanerpes pucherani ${ }^{\mathrm{c}}$ & 1 & 1 & $0-4$ & 2.2 & - & $<1$ \\
\hline Pipra mentalis & 3 & 4 & $1-2$ & 1.2 & 3 & 1 \\
\hline Rhytipterna holerythra & 1 & 2 & $1-2$ & 1.5 & 2 & 3 \\
\hline Tityra semifasciata & 4 & 11 & $0-7$ & 2.3 & 6 & 5 \\
\hline Querula purpurata & 2 & 8 & $1-1$ & 1.0 & 4 & 2 \\
\hline Myiodynastes maculatus & 1 & 10 & $1-11$ & 4.0 & 8 & 8 \\
\hline Myiarchus crinitus & 2 & 20 & $1-5$ & 2.8 & 11 & 11 \\
\hline M. tuberculifer & 2 & 2 & $1-2$ & 1.5 & 2 & 1 \\
\hline Contopus spp..$^{\circ}$ & 1 & 3 & $0-2$ & 1.1 & - & 1 \\
\hline Catharus ustulatus & 3 & 68 & $0-3$ & 1.2 & 24 & 16 \\
\hline Vireo olivaceus & 5 & 55 & $0-3$ & 1.3 & 20 & 14 \\
\hline Vermivora peregrina & 5 & 91 & $0-4$ & 1.1 & 27 & 19 \\
\hline Dendroica pensylvanica ${ }^{\mathrm{c}}$ & 1 & 1 & $0-1$ & 1.1 & - & $<1$ \\
\hline Piranga rubra & 1 & 1 & $0-3$ & 1.5 & - & $<1$ \\
\hline Small birds (spp.? $)^{\mathfrak{c}}$ & 2 & 9 & $0-2$ & 1.1 & - & 2 \\
\hline
\end{tabular}

a Visits with complete data on seed ingestion

- Estimated as (visits $\times$ seeds/visit)/(total seeds eaten) $\times 100$

- Estimated from weight/ingestion regression - see text

In both cases, the capacity to remove seeds seems to depend on the size of the bird rather than any specialized behavior (cf. Howe, 1977). No species of visitor was seen on more than 5 of the 12 days of observation. There was little overlap in visitation on the two days (four days apart) that the same tree was watched; of 6 visitor species on the first day, 2 reoccurred among the 5 species on the second day. No species accounted for more than $19 \%$ of the total seed crop removed. There is no evidence from this study of close interpendence of any particular visitor species and Guarea glabra.

An important distinction can be made between the effects of visitation by migrants and by tropical residents on the dispersal of Guarea (Table 2). Migrants averaged lighter in weight than residents $(21 \pm 11$ versus $106 \pm 110 \mathrm{~g}$; Walsh's $t=2.65,13 \mathrm{df}, P=0.02)$ and consequently ate fewer seeds per visit $(1.4 \pm 0.6$ versus $2.9 \pm 2.7$; Walsh's $t=1.90,12 \mathrm{df}, P<0.1)$. However, migrants visited the tree more often than residents $\left(X^{2}=213.4,1 \mathrm{df}, P \ll 0.001\right)$, and consequently removed disproportionately more seeds than residents $\left(X^{2}=81.0,1 \mathrm{df}, P \ll 0.001\right)$. Inspection of the table indicates that four migrant species ( $M$. crinitus, C. ustulatus, V. olivaceus, and V. peregrina) removed aproximately 60 percent of the seeds eaten by birds. No resident species accounted for the removal of as many seeds as any one of these four migrants. The conclusion is warranted that the seeds of Guarea glabra are primarily dispersed by small migrant oppor- 
tunists (all of which are primarily insectivores on breeding grounds), although a variety of local birds also eat the arilloids.

All of the species listed are likely to be dispersers rather than seed predators or "fruit thieves" (cf. Howe 1977). None have seed-crushing bills or belong to taxa known to possess internal organs for crushing hard seeds (cf. Ziswiler and Farner, 1972), nor did any habitually drop seeds under the tree (cf. Howe, 1977). Most are known to regurgitate softer seeds than Guarea (Howe, 1977; Howe and Estabrook, 1977; Howe and Vande Kerckhove, 1978; pers. obs.). Ramphastos, Myiarchus, Vermivora, and Vireo regurgitated Guarea seeds in nearby vegetation, and Querula defecated intact seeds of this species. Treatment effects are not known for three of the infrequent visitors (Contopus, Dendroica, Piranga).

Aggressive encounters between visitors were surprisingly rare, considering that several birds were often in the same small tree. During $60 \mathrm{~h}$ of observation, there were 6 apparent chases. Of 4 intraspecific encounters between Catharus, three resulted in displacement from the tree. One Trogon rufus chased a Catharus from the tree, and one Catharus displaced a Vermivora. This low level of aggressive interaction and the apparent superabundance of fruit suggest that competition is negligible.

Not all insectivores opportunistically attempted to eat arilloids that were readily available. A small flycatcher (Tolomyias assimilis) and an antshrike (Thamnophilus punctatus) were frequent visitors to this and neighboring trees. On one occasion each of these was observed to extract an insect from an open Guarea capsule in which arilloids were plainly visible. Neither bird attempted to extract seeds.

\section{Production, Visitation, and Dispersal Success}

Visitation increases with fruit production, as indicated by positive correlations between the number of individuals visiting a tree and the number of arilloids available (Fig. 2 a), and the number of species visiting a tree and arilloid availability (Fig. 2b). The correlation coefficient for the plot of individuals versus arilloid availability is inflated because the sample trees fell into two groups - those with few and those with many capsules open. However the relation is almost certainly biologically appropriate. The correlation between species visitation and arilloid availability is direct and robust. Neither plot suggests a disproportionate increase in visitation with an increase in fruit production; both relationships appear roughly linear.

As might be expected from the relationship between visitation and fruit production, the number of seeds removed increased with fruit production (Fig. 3 a). The correlation coefficient is again inflated by the distinction between small and large plants, but the dichotomy appears to be accentuated by biological factors. The three large trees attracted 8 of the 11 Pteroglossus observed (this species eats more seeds per visit than most birds) and most of the effective migrant dispersers. The latter included 49 of the 68 Catharus, 18 of the 20 $M$. crinitus, and 79 of the 91 Vermivora. More migrants occurred at these trees 

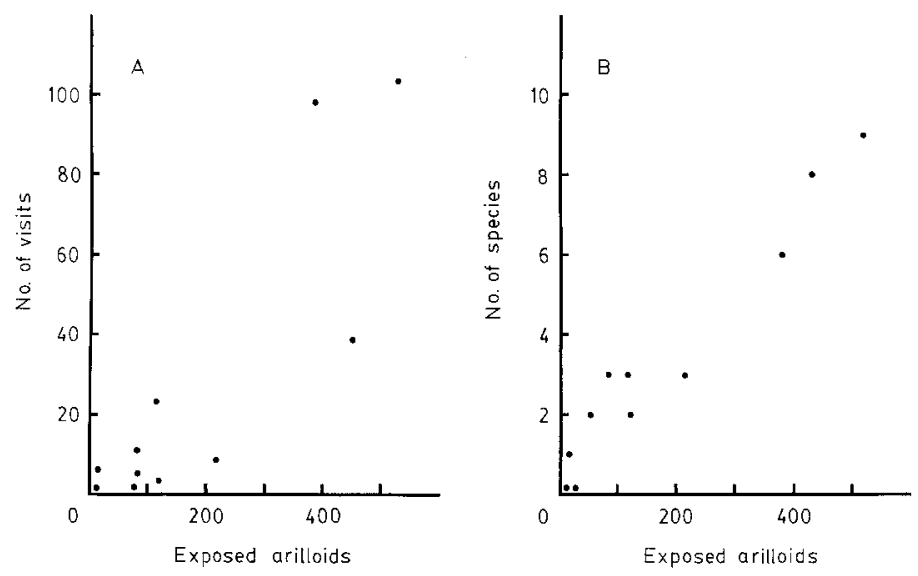

Fig. 2A and B. Relationships between visitation and the size of the available crop. A Correlation between the number of visits and the number of arilloids exposed $(r=0.85, P<0.01)$. B Correlation between the number of species of frugivores eating fruit and the number of arilloids exposed $(r=0.77, P<0.01)$
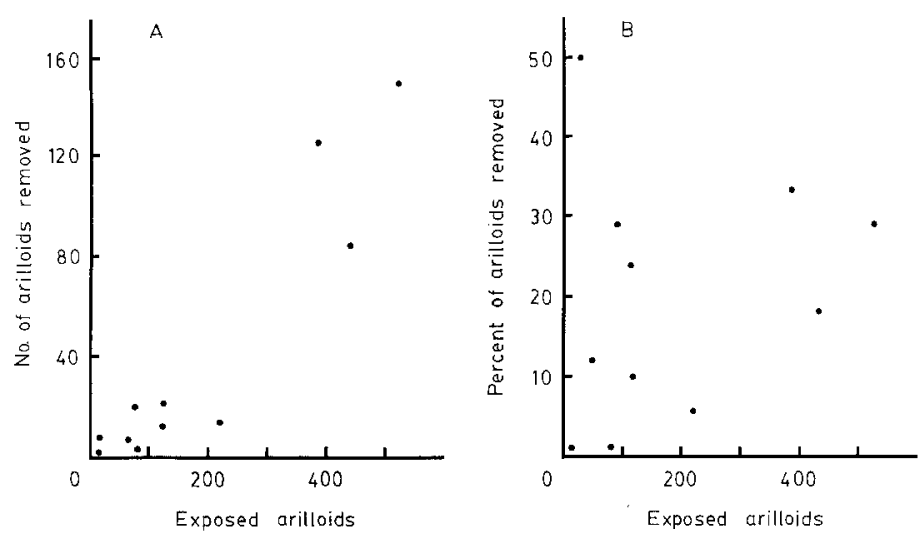

Fig. 3 A and B. Relationships between removal success and the size of the available crop. A Correlation between the number of arilloids removed and the number available $(r=0.93, P<0.01)$. B Nonsignificant correlation between the percent of arilloids taken and the the number available $(r=0.23)$

than would be expected from the number of fruit available $\left(X^{2}=16.2,1 \mathrm{df}\right.$, $P<0.001)$. There is clearly no significant relationship between the percent of the available crop removed and the number of arilloids available (Fig. $3 \mathrm{~b}$ ). Even when the extreme point is removed $(16,50 \%)$, the slope of the line is not significantly different from zero $(r=0.53, P>0.05)$. It is clear that removal success (from the plant's perspective) does not increase disproportionately with crop size, but that visitation and seed removal simply reflect the number of arilloids available. Effects of disperser variety on seed dissemination are presently unknown. 


\section{Mammal Visitation}

Two species of mammals visited Guarea, but neither dispersed seeds. Squirrels (Sciurus granatensis, Sciuridae) spent $98 \mathrm{~min}$ in a tree with 538 arilloids exposed, $72 \mathrm{~min}$ in a tree with 384 arilloids exposed, and $9 \mathrm{~min}$ in a tree with 116 exposed. During these visits, $S$. granatensis neither killed nor dispersed seeds, but peeled the arils and dropped seeds under the crown at a rate of $4.4 \pm 1.0$ per min during active feeding. Actual rates for entire visits cannot be computed, as the relative time spent eating, searching, and resting could not be determined in thick foliage. An agouti (Dasyprocta punctata, Dasyproctidae) chewed and killed seeds under a Guarea on at least one occasion. It did not bury any or carry any away. Bats are unlikely to be attracted to a scentless orange aril (van der Pijl 1972), and none have been known to eat Guarea during several years of study of frugivorous species on Barro Colorado Island (D. Morrison and T. Werner, pers. comm.).

\section{Discussion}

This study provides a needed quantitative comparison with earlier attempts to study plant/frugivore interactions in tropical forests, as well as unique information concerning the poorly known relationships between Guarea glabra and its disperser assemblage. Among the unique data are those concerning fruit production and subsequent visitation rates and dispersal success, the "tactics" employed by this tree in recruiting dispersal agents, and the relative importance of resident and migrant birds in the dissemination of seeds from fruit adapted for the attraction of "opportunists."

As predicted, a large and taxonomically diverse assemblage of birds utilized the fruit of Guarea glabra. Equally important, there was no evidence that any one species of bird was dependent on the plant, nor that the plant depended on any single species of bird. Of the 19 visitor species, none removed more than $19 \%$ of the seeds eaten by birds. In contrast, Howe and Vande Kerckhove (1979) documented seed dispersal of a small Costa Rican tree (Casearia corymbosa H.B.K., Flacourtiaceae) at which fruit crops were regularly stripped within an hour of discovery by birds. Of the 14 species visiting the Costa Rican plant, one vireo (Vireo flavoviridis) accounted for more than $70 \%$ of the visits and $65 \%$ of the seeds removed. Casearia seeds were two to three times the bulk of Guarea seeds, and were surrounded by a substantial oily aril. Howe and Vande Kerckhove suggested that competition among potential dispersers for a limited and highly nutritious food resource led to facultative specialization by one frugivore species. The ecological outcome was a known and accessible source of food for the bird and reliable visitation for the plant. A similar rapid depletion of large-seeded arilloids by a single disperser has been noted in the larger rainforest ecotype of C. corymbosa (Howe, 1977) and in a Panamanian nutmeg (Virola sebifera Aubl., Myristicaceae) (Howe, unpublished). The relevant dispersers were a small cotinga (Tityra semifasciata) and a toucan (Ramphastos swainsonii), respectively. While these earlier studies suggest that 
some tree species promote competition for dispersers that results in specialization within the frugivore assemblage, the present study suggests that a superabundant fruit promotes widespread use by a variety of species. All of these studies add cogency to the argument that the degree of competition induced by the plant affects the numerical size and richness of the assemblage, and implies that different "ecological syndromes" of fruit production may lead to quite different modes of dispersal by birds (McKey, 1975; Howe and Estabrook, 1977).

Intraspecific variations in the number of fruit produced per day and factors related to dispersal success shed light on the "tactics" employed by Guarea for effecting reproduction through recruitment of dispersal agents. As predicted for a plant with the "superabundance" syndrome, both numerical visitation and the richness of the disperser assemblage increased with the size of the available crop. One resulting measure of dispersal success was a linear increase in the number of seeds removed as the number of arilloids available increased; large trees definitely disperse more seeds than small ones. This result must be viewed in light of the tendency of squirrels to visit especially fecund trees and drop seeds underneath crowns; large plants may enhance removal of seeds by birds at the expense of wastage by non-disperser mammals (cf. Howe and Estabrook, 1977). But the numerical differences in success between large and small plants are clear. There is no indication, as found for C. corymbosa, of curvilinearity in the relationship between the number of seeds removed and the size of the available crop (Howe and Vande Kerckhove, 1979).

An intriguing negative result is that the proportion of seeds removed does not increase or decrease with the size of the available crop; the proportion removed is independent of the number exposed. Where dispersers are scarce, assemblage satiation may result in proportionately fewer seeds being removed at exceptionally fecund plants than at others (Howe and Vande Kerckhove, 1979). Where dispersers are abundant, plants may be selected to attract a disproportionate number through showy displays; the proportion of seeds removed should increase with the size of the available crop (Howe and Estabrook, 1977; cf. Janzen, 1967). The absence of a consistent relationship at Guarea indicates neither a depression due to disperser satiation nor an advantage due to enhanced display independent of fecundity itself. Squirrels might depress the success of especially fecund plants, but it appears likely that lifetime schedules of fruit production at this plant (Fig. 1) reflect selection on other life history traits rather than selection due to particular disperser attributes. The simplest description of the dispersal "tactic" of Guarea glabra is the production of superabundant arilloids of individually low nutritional quality as a means of attracting a variety of potential dispersers. One possible advantage of the "superabundance syndrome" is dissemination of seeds to a variety of suitable sites by birds with different habits (Snow, 1971; Howe and Estabrook, 1977); a probable advantage is the avoidance of an obligate dependence on particular species of frugivores (cf. Baker and Hurd, 1968).

Largely because tropical wet forests were believed to exist in competitive equilibrium, ornithologists have thought that North American migrants must 
exert a strong competitive effect on local species (MacArthur, 1972). Leck (1972) rejected such an interpretation for birds visiting fruiting trees in the laboratory clearing on Barro Colorado Island because migrants were infrequent visitors at the species that he watched. Migrants predominated at Guarea glabra and accounted for most of the arilloids removed. But there was still no evidence of competitive effects on local species, since fruit appeared superabundant, aggression was negligible, and local species were haphazard visitors. The four visitors most frequently observed at Guarea (M. crinitus, C. ustulatus, V. olivaceus, and $V$. peregrina) are known to be abundant in Central Panama during spring migration (Wetmore, 1972; Ridgely, 1976), and may not have been detected by Leck because his observations were confined to different species of trees in highly disturbed habitat. Our observations were made in more typical habitat deep within the forest (1-2 km from the laboratory clearing). We concur with other workers that postulated competitive effects must await direct evidence that competition occurs or that equilibrial communities exist (Wiens, 1977; Connell, 1978).

The preponderance of North American migrants at Guarea glabra raises questions about the ecological significance of dispersal of this species as well as about the effects of bird migration on fruiting phenology. Proctor (1968) documented passage times of seeds in the digestive tracts of shorebirds that were long enough to result in the dispersal of viable seeds for thousands of kilometers. Such long-distance dispersal is unlikely in Guarea. The seeds are bulky and migrants regurgitate them promptly (e.g. 5-20 min). As these birds migrate by night, very few (if any) seeds are likely to leave the Barro Colorado forest. The one frugivore known to pass these seeds through the gut (Querula) is a local species confined to breeding areas during this season. Occasional range extensions mediated by migrants may occur, but the great majority of dispersal events are theoretically analagous to dissemination to temporarily vacant sites in "saturated" habitat (Williams, 1975; Hamilton and May, 1977). An additional possible selective factor is local escape from heavy seed or seedling mortality near the parent tree (Janzen, 1970); few juveniles occurred under adult trees despite heavy seed fall. It would be instructive to know if migrants are predominant dispersers of this plant throughout its range; if so, the fruiting phenology should be adaptively keyed to spring migration. A test would require data from other parts of the range. One expects earlier fruiting seasons in South America and later ones in northern Central America and Mexico, coincident with massive northward movements of much of the North American avifauna. If demonstrated, such relationships would suggest loose "coadaptation" of this plant and a guild of opportunistically frugivorous migrants.

Acknowledgements. This study was conducted at the Smithsonian Tropical Research Institute, Balboa, Canal Zone. The senior author was supported by a Smithsonian Postdoctoral Fellowship and the junior author by a Noble Foundation Grant to the Smithsonian Tropical Research Institute. We are grateful to R.W. Storer for access to specimens under his care in the Bird Division of the Museum of Zoology, University "of Michigan, Ann Arbor. 


\section{References}

Baker, H.G., Hurd, P.D. : Intrafloral ecology. Ann. Rev. Entom. 13, 385-414 (1968)

Bawa, K.: Breeding systems of tree species of a lowland tropical community. Evolution 28, 85-92 (1974)

Connell, J.H.: Diversity in tropical rain forests and coral reefs. Science 199, 1302-1310 (1978)

Frankie, G.W., Baker, H.G., Opler, P.A.: Comparative phenological studies of trees in tropical wet and dry forests in the lowlands of Costa Rica. J. Ecol. 62, 881-919 (1974)

Hamilton, W.D., May, R.M.: Dispersal in stable habitats. Nature 269, 578-581 (1977)

Howe, H.F.: Bird activity and seed dispersal of a tropical wet forest tree. Ecology 58, 539-550 (1977)

Howe, H.F., Estabrook, G.F.: On intraspecific competition for avian dispersers in tropical trees. Amer. Natur. 111, 817-832 (1977)

Howe, H.F., Vande Kerckhove, G.A.: Seed dispersal by birds and the fecundity of a tropical tree. Ecology (in press) (1979)

Janzen, D.H.: Synchronization of sexual reproduction of trees within the dry season in Central America. Evolution 21, 620-637 (1967)

Janzen, D.H.: Herbivores and the number of tree species in tropical forests. Amer. Natur. 104, $501-528(1970)$

Leck, C.F.: The impact of some North American migrants at fruiting trees in Panama. Auk 89, 842-850 (1972)

Leigh, E.G. Jr:, Smythe, N.: Leaf production, leaf consumption, and the regulation of folivory on Barro Colorado Island. In: The ecology of arboreal folivores (G. Montgomery, ed.). Washington: Smithsonian Institution Press (1978)

McKey, D.: The ecology of coevolved seed dispersal systems. In: Coevolution of animals and plants (L.E. Gilbert, P.H. Raven, eds.), pp. 159-191. Austin: University of Texas Press 1975

MacArthur, R.: Geographical ecology. New York: Harper and Row 1972

Pijl, L. van der: Principles of dispersal in higher plants, 2nd Ed. New York: Springer-Verlag 1972

Proctor, V.W.: Long-distance dispersal of seeds by retention in digestive tract of birds. Science 160, 321-322 (1968)

Regal, P.J.: Ecology and evolution of flowering plant dominance. Science 196, 622-629 (1977)

Ridgely, R.S.: A guide to the birds of Panama. Priceton: Princeton University Press 1976

Smith, C.E. Jr.: Flora of Panama, Part VI, Family 92, Meliaceae. Ann. Missouri Bot. Garden 52, 55-79 (1965)

Snow, D.W. : Evolutionary aspects of fruit-eating by birds. Ibis 113, 194-202 (1971)

Wetmore, A.: The birds of the Republic of Panama, Part 3, Passeriformes: Dendrocolaptidae (Woodcreepers) to Oxyruncidae (Sharpbills). Washington: Smithsonian Institution Press 1972

Weins, J.A.: On competition and variable environments. Amer. Scientist 65, 590-597 (1977)

Williams, G.C.: Sex and evolution. Princeton: Princeton University Press 1975

Ziswiler, V., Farner, D.S.: Digestion and the digestive system. In: Avian Biology, Vol. 2 (D.S. Farner, J.R. King, eds.), pp. 344-430. New York: Academic Press 1972

Received December 1, 1978 